\title{
Audiovisual content as a learning aid for Business English learners: developing and validating a Matrix
}

\author{
Carvalho, Tiago ${ }^{\text {a }}$ Almeida, Pedro ${ }^{\text {a }}$ and Balula, Ana ${ }^{\text {b }}$
}

${ }^{a}$ Digimedia, Universidade de Aveiro, Portugal, ${ }^{\mathrm{b}}$ CIDTFF, Universidade de Aveiro, Portugal.

\begin{abstract}
Audiovisual content (AVC) consumption, namely in Online Collaborative Platforms (OCP), like YouTube $\bigcirc$, has been growing, mostly for entertainment purposes. Additionally, AVC has been regularly used to support educational contexts, either in formal local scenarios or to support online courses. But educational practitioners lack a structured place to find which AVC to use for each learning objective. This context provided the opportunity to develop an OCP to support crowd mapping of AVC and to serve as an online AVC aggregator for teachers and learners. This paper reports on a proposal for Business English training. This OCP needs to be sustained by a Matrix which crosscuts AVC according to parameters identified in the literature review. Experts in the fields of English as Foreign Language Didactics and Educational Technologies were asked to validate the Matrix in its cataloging and searching features. Data was gathered via semi-structured interviews and treated by means of content analysis. The data analysis suggests that, even though it may be improved, the Matrix allows for accurate cataloging. The concept of the OCP was validated and deemed as a learning aid with potential. The following steps include the design and construction of a prototype of the OCP.
\end{abstract}

Keywords: Audiovisual Content; Digital Platforms; English as Foreign Language; Didactics 


\section{Introduction}

Online Collaborative Platforms (OCP) that serve as a repository for Audiovisual Content (AVC), like YouTube $\subset$, have seen constant growth of users. According to this global platform's press releases ${ }^{1}$, over one billion people use YouTube $\odot$ for several reasons, being the most prominent one entertainment, amounting to over one billion hours of viewed AVC. With this potential, it is no wonder that English as Foreign Language (EFL) learning videos proliferate, with users and institutions dedicating whole channels to EFL - like B.B.C. or British Council. However, too much choice of AVC presents a problem: educational practitioners lack a structured place to find which AVC to use for each learning objective.

This context provided the opportunity to conceive and develop a doctoral research project to implement an OCP to support crowd mapping of AVC and to serve as an online AVC aggregator for teachers and learners. This OCP is meant to be a valuable tool for (in)formal EFL learning scenarios, with two primary functions: i. to support crowd mapping of AVC, and ii. to serve as an online AVC aggregator for teachers and learners of Business English (BE). The development of such a platform has to be grounded on a mapping Matrix, which crosscuts AVC and BE learning objectives. Ergo, this mapping Matrix will address several AVC features, not only at the structural, situational or communicational level, but also as to the language proficiency level (according to the Common European Framework of Reference for Languages ${ }^{2}$, and communication skills associated to BE. Conceptualizing and developing this Matrix was Phase 1 of the project.

Phase 2 consisted of an expert validation of the Matrix, and the most relevant results of this Phase will be addressed in this paper. Thus, the choice of the expert panel, as well as the decisions to collect and treat the data will be depicted in the methodology section. The discussion section focuses on the constraints experts identified during their trial of the Matrix and the possibilities to overcome them to embody the Matrix into the OCP successfully.

\section{State of the art}

The theoretical background of this research project attempted to provide a reliable basis to unite published knowledge in three fields: i. EFL didactics (specifying the theoretical grounds for BE); ii. the tendencies of AVC consumption (specifying the published practices of using AVC in English didactics; and iii. the role of OCPs in autonomous language learning.

\footnotetext{
${ }^{1}$ See https://www.youtube.com/yt/about/press/

${ }^{2}$ see https://www.coe.int/en/web/common-european-framework-reference-languages/level-descriptions
} 
One can initiate this revision of the state of the art with the measure in which AVC is still a highly-favored form of entertainment. Consumer statistics published by Nielsen $(2014)^{3}$ indicate a growth of hours dedicated to AVC consumption in all demographics. Google $(2016)^{4}$ adds statistics about the different ways of viewing over one billion hours of $\mathrm{AVC}^{5}$, namely using computers or mobile devices, as well as pairing the mobile devices with AVC consumption. Using YouTube $(\mathcal{C}$ as a reference, one can also highlight that the most searched AVC are related to music, movies and User Generated Content (UGC); 4\% of uploaded content addresses science and technology; and $40 \%$ of YouTube $\odot$ views are done on mobile devices ${ }^{5}$. In conclusion, all data points to the fact that AVC, as an entertainment form, is consumed massively, using several platforms, on a global scale.

Adding to the previous conclusion there is the fact that for economic, political and social reasons, English is the "lingua franca of the modern globalized world" (Crystal, D. 2005, p. 1). This fact can also be confirmed by the amount of English speaking AVC on repositories and television program grids of Portuguese channels.

The entertainment power of AVC has raised the curiosity of EFL researchers. Such a wide variety and range of AVC provided theoretical approaches to using AVC for EFL didactics. McNulty \& Lazarevic (2012) list some advantages of using AVC in English didactics like: synchronous communication exposure, non-verbal communication, paralinguistic cues and a more efficient understanding of meaning. However, Bahrani et al. (2014) identify some of the constraints relating to the same issue, like: biased cultural content, unsuitability of genre or exposure to irrelevant/difficult vocabulary. Platforms like FluentU (www.fluentu.com) use AVC from online repositories as the leading learning aid in their structured training courses for adult EFL learners. Moreover, platforms like Future Learn (www.futurelearn.com) and Khan Academy (https://pt-pt.khanacademy.org/) invest in their own production of AVC for their training courses.

Researchers also studied the effect of using collaborative platforms in the teaching/learning of EFL. Being a technology that rose with the evolution of Web 2.0, this topic is still in need of additional study. Nevertheless, video-based Massive Online Open Courses got positive responses in a study by Bárcena et al. (2014), and Duolinguo (www.duolinguo.com), a mobile collaborative language learning platform, was positively reviewed by Hockly (2015). This theoretical background, confirmed the need for the OCP under development, leading to the presentation and execution of this research project.

\footnotetext{
${ }^{3}$ See http://ec.europa.eu/eurostat/documents/3433488/5281333/KS-SF-09-044-EN.PDF/82cd034b-a65f-47ca-8f62-6285ad593c20

${ }^{4}$ See https://www.consumerbarometer.com/en/graph-builder/?question=M8\&filter=country:portugal\%7CC1:16_24,25_34,35_44

${ }^{5}$ See https://www.socialmediatoday.com/social-business/mind-blowing-youtube-stats-facts-and-figures-2017-infographic
} 


\section{Development of the Matrix}

This Matrix is an aggregation of markers considered essential to catalog AVC which targets educational needs of BE learners. To identify these markers, an exploratory study was conducted in the literature and online AVC repositories and aggregators. Thus, the Matrix was designed and developed considering data collected in $\mathbf{i}$. the state of the art, - here one gathered AVC features valued by EFL researchers, like type of AVC, subtitles, or new content feedback; ii. the European Common Framework of Reference ${ }^{6}-$ to legitimize the proficiency levels and the communicative contexts; iii. published research studies on AVC and on EFL didactics to collect elements that learners of EFL valued when watching AVC as an aid to their learning ${ }^{7}$ - like accents, fluency, or vesimilitude; and iv. exploratory studies of OCP's connecting AVC and EFL to verify how these platforms were constructing their search queries, and how they indexed the AVC and the lesson plans.

Afterwards, using the tool Google Forms $\odot$, the Matrix evolved into a set of questions about AVC, thus inviting users to attribute the markers to the content, i.e., an indexation of content but focused on both AVC and learning objectives. Figures 1, 2, 3 and 4 provide examples of markers, how these markers were transformed into a questionnaire and their answer options.

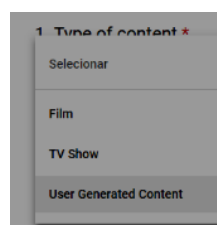

Figure 1-Choosing the type of the AVC
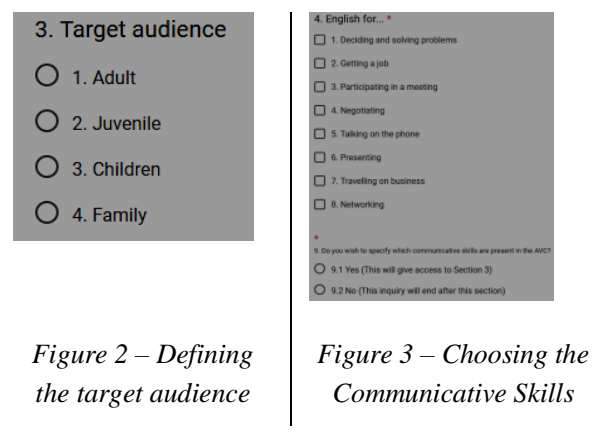

The questionnaire that derives from the Matrix is divided into three sections, and all questions are to be answered after the viewing of a single AVC. Section 1 asks about information about the general identification elements of the AVC and the reason why it was uploaded. Here, one answers questions about the "Type of $A V C$ " (Figure 1) "Title", "Year", "Description" and "URLs". Section 2 asks about AVC meta-data and linguistic markers: "Genre", "Duration", "Target audience" (Figure 2), "Communicative Skills" (Figure 3), "English level", "Subtitles", "Content Feedback" and Communicative Contexts. Section 3

\footnotetext{
${ }^{6}$ See https://rm.coe.int/16802fc 1 bf

${ }^{7}$ These elements were collected from Carvalho \& Almeida (2015)
} 
is an optional section that asks users to specify the Communicative Skills ${ }^{8}$ of the AVC (Figure 4).

Grounding the OCP on this Matrix allows both the cataloging and the search for AVC. Moreover, it will legitimize the primary functions of the OCP (see introduction). This Matrix's development was in tune with all the information collected from the exploratory work mentioned in the beginning of this section.

\section{Methodology}

After the development Phase, an experimental and validation Phase of the Matrix was carried out. Getting a variety of expert viewpoints about its accuracy was fundamental. It was also an opportunity to gather recommendations to embody the Matrix in an OCP. This need for expert perspectives led to the choice of the methodological process: Expert panel validation.

Data were collected using three instruments. i.e., i. an observation grid, which was used by the researcher to evaluate the Experts' reactions to the Matrix in loco; ii. a survey elaborated under the Atrakdiff ${ }^{9}$ methodology for evaluation of products; and ii. a semistructured interview, to collect the experts' viewpoints and recommendations. The gathered data were treated as qualitative data by means of content analysis ${ }^{10}$.

One of the first decisions in selecting a review panel is to define the necessary expertise of its members. Experts can be identified by specific characteristics, i.e., "An expert has documented (...) experience with the target population; achieved professional certification in a related topic area (...); or initiated research on the topic area" (Davis, 1992, p. 1). Using these perspectives, the following criteria to select experts for the panel were outlined. Namely, their expertise in i. EFL didactics; ii. EFL learning with AVC; iii. AV consumption; iv. development-research methodology; v. use of OCP's in educational contexts.

Furthermore, the interview was also used to gather data about their beliefs and opinions. According to Harrell \& Bradley (2009), the type of interview that best suits the intended purpose is the semi-structured interview, once it allows for a more systematic treatment of the data, and it is flexible enough to select, mid-interview, subjects that need further deepening. With a balanced amount of control and a set of open questions, the semistructured interview can also accommodate new (in vivo) items. Therefore, interviewing experts was fundamental to i. identify the interviewees' global perception concerning the

\footnotetext{
${ }^{8}$ The Communicative Skills adopted by the Matrix were collected from Carvalho, Almeida, Balula (2017).

${ }^{9}$ See https://www.uid.com/en/publications/attrakdiff

${ }^{10}$ This methodological procedure was influenced by Ghiglione \& Matalon's (2001) terminology concerning content analysis.
} 
mapping accuracy and range of the Matrix; ii. validate the linguistic formulation and variables included in the Matrix; iii. validate the modules' considered; iv. validate the tool used to search mapped AVC. Experts were also asked to provide opinions on how to operationalize the Matrix in an OCP, pinpointing possible threats to the platform - by predicting user behavior - and suggesting strategies to overcome the identified threats.

To facilitate the data analysis and respect the experts' anonymity, first, a code was defined for each interviewee - Ed1, Ed2, Et1, and Et2; second, the interviews were recorded and transcribed in full; and, finally, treated resorting to Content Analysis. In the latter, the objectives and a set of categories were defined beforehand whereas the subcategories were defined in vivo, resulting in the following category structure (see Table 1).

Table 1. Categories of the content analysis according to the defined objectives

\begin{tabular}{lll} 
Objectives & Categories & Subcategories \\
\hline $\begin{array}{l}\text { 1. Objective 1 - to Identify the } \\
\text { interviewees' global perception } \\
\text { concerning the mapping accuracy and } \\
\text { range of the Matrix }\end{array}$ & $\begin{array}{l}\text { 1.1. Mapping } \\
\text { accuracy }\end{array}$ & $\begin{array}{l}\text { 1.1.1. Structure } \\
\text { 1.1.2. Content }\end{array}$ \\
\cline { 2 - 3 } $\begin{array}{l}\text { 2. Objective 2 - to validate the } \\
\text { linguistic formulation and variables } \\
\text { included in the Matrix }\end{array}$ & $\begin{array}{l}\text { 2.1. Linguistic } \\
\text { accuracy }\end{array}$ & $\begin{array}{l}\text { 2.1.1. Types of AVC } \\
\text { 1.2.2. English proficiency }\end{array}$ \\
\hline \multirow{3}{*}{$\begin{array}{l}\text { 3. Objective 3 - to validate the } \\
\text { modules' considered }\end{array}$} & 3.1. Suitability & $\begin{array}{l}\text { 3.1.1. Purpose of question } \\
\text { 3.1.2. Relevance of questions }\end{array}$ \\
\cline { 2 - 3 } & 3.2. Organization & $\begin{array}{l}\text { 3.2.1. Sublevels } \\
\text { 3.2.2. Misplaced questions }\end{array}$ \\
\hline 4. Objective 4 - to validate the tool & 4.1. Filters & 4.1.1. Criteria \\
\cline { 2 - 3 } used to search mapped AVC & 4.2. Result display & \\
\hline
\end{tabular}

The meetings with the Experts consisted of three moments. In the first moment, the Expert, or Interviewee (Ie), watched a video. Then, the Ie used the questionnaire to catalog the video, while being observed by the Interviewer (Ir). This task was carried out a second time, and at the end of the task, Ie filled out the AttrakDiff questionnaire. Finally, Ir asked scripted questions about the experience. In the second moment, the Ie experimented with the search questionnaire, guided by the Ir. The Ir provided a video as a possible search result, which Ie watched. Ie was asked about the search tool, the quality of the filter and the information to be displayed in a search result. In the third moment, Ir asked questions about the operational aspects to embody the Matrix in an OCP. After the interviews with the four Experts, there was enough data to address the objectives. 


\section{Discussion}

The discussion section will focus on expert feedback directed to the Objectives listed in the previous section. The discussion will address the questions that Experts considered to be needing improvement. The sub-categories that were validated, like "Structure" (1.1.1.), "Content" (1.1.2.), "Types of AVC" (1.2.1.) or "English Proficiency" (1.2.2.) will not be discussed.

Regarding "Suitability" and in terms of "Purpose of questions" (see Table 1, 3.1.1.), Et1 disagreed on using the question about "Title of video" (Figure 5) to write the actual title the video has on the repository it was uploaded from. Et1 states that "The title should be the 'didactic' reason why I'm including the AVC in the platform", because this OCP's purpose is not to index AVC by title but rather by why the user considered this worthy of sharing.

The question "Relevance of questions" (Table 1, 3.1.2.) Subcategory 3.1.2. was addressed by Ed2, who used the example of the question about "Genre" (Figure 6) to inquire the need and relevance of so many options to answer some of the questions: "I don't know if all that is here is equally relevant."

Concerning "Sublevels" (3.2.1.), Ed1 and Et2 addressed the subjectivity of the sublevels for the "Target-audience" (Figure 2) question. For Ed1, the chosen options need to be reviewed as they will create doubt on mainly teenage learners' perception: "Juvenile? Adult? Teenagers normally have problems. From 18 one is already an adult" (Ed1).

As for "Misplaced questions" (3.2.2.), Et1 pinpointed the lack of relevance of the "Description of the AVC" (Figure 7) question. To this expert, the description is "critical for this cataloging!", which means that it needs a more highlighted position in the questionnaire and also to lose its optional status.

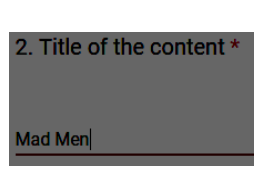

Figure 5-Copying title of $A V C$
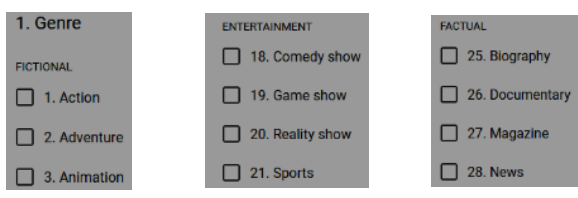

Figure 6-Choosing Genre

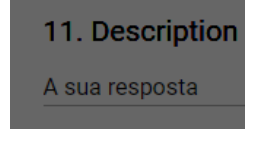

Figure 7 -Describing the AVC

Concerning the display of search results (Table 1, 4.2.), Experts suggest that the OCP present more than one result, even if it does not match the search criteria by 100\% (Et1, Ed2). Experts also suggest showing basic information about the AVC on the result list, namely "relevance towards the search criteria" (Et2), "the communicative situation and the level. Eventually the duration" (Et2). Additionally, the results list should also present the number of times the AVC was cataloged (Ed2). 
For the issues raised, seven solutions were equated: i. to create a user profile which can collect much of the information that the questionnaire asks for - e.g. preference for "Genre" and for "Communicative contexts"; ii. to provide three levels of cataloguing, direct, basic and advanced; iii. to eliminate irrelevant questions from the questionnaire (for instance, if a user chooses a UGC, the OCP will not ask about the episode, season or producer); iv. to add the option "others" in some of the questions. There is also the possibility to add an item for "comments", to add information not provided by the Matrix's questionnaire (it is necessary that these additions do not conflict with the issue of "too many sublevels"; v. to change the item "Title of the video" to "Purpose of the video" with an explaining pop-up balloon clarifying that the information to be written would be the didactic purpose(s) of this video; vi. to make "Description" a mandatory and highlighted question of the cataloguing process; vii. changing the question from "Target audience" to "Age groups" and the sublevels would be the ones proposed by the manuals and online platforms of EFL learning, namely: "Young learners"; "Teenage learners"; "Adult learners".

The experts were also asked to identify some threats to consider in the operationalization process of the OCP. One of the pinpointed threats was the possibility that the crowdsourcing element of the platform may not function due to a lack of participation by the target users (because "cataloging is a dull task" (Et1)". Moreover, users need to see an apparent value of the OCP for their teaching/learning practice and be rewarded for their work (Ed2, Et2). To circumvent these threats, the technological Experts suggested that the OCP should be developed with gamification features that will provide users with the participation rewards. Other contribution strategies proposed were: creating a business model, connecting the OCP with educational institutions, and integrating social interaction features.

\section{Conclusions}

Phase 2 of this research project consisted of asking experts for the validation of the core concept of the OCP, for feedback about the Matrix, and for suggestions about incorporating the Matrix in the OCP. After following all methodological procedures and subsequent analysis of the data, it was clear that all experts saw value in the development of this OCP, thus giving their validation to the global scope of the research.

Moreover, the Experts did not consider any items of the Matrix to be redundant. The main concerns about the questionnaire are the unnecessary amount of answer options and a rigidity of some questions. Still, all items were considered relevant for the mapping and search process. Some of the items were highlighted as more significant, which is relevant 
when organizing the mapping questionnaire in the OCP - ideally with three levels of mapping.

On an operational level, Experts shared some strategies to circumvent the threats they pinpointed to the OCP, like using gamification features, develop a business model to guarantee user participation, promote cooperation with educational institutions and develop social interaction features between the target-users.

Among the opportunities that Experts recognized in the project, one can mention the value it would bring in extracurricular contexts, namely putting the focus of choice on the learner, thus making the learner responsible for the progress of his/her learning. Another opportunity is related to the enrichment of the teaching/learning context with rich and free material provided by the online AVC repositories. This last opportunity can also be transported to the classroom context, reinstating the importance of AVC as an aid in EFL classes.

\subsection{Future work}

Future work on this project will consist of two further Phases. The objective of the next Phase is the construction of the OCP's prototype, taking into consideration the feedback shared by the Expert Panel. The research team will complement this development with continuous reflection, by providing guidelines and improvement suggestions. The team will test the OCP and define the AVC which will be used in the validation process planned for Phase Four.

The purpose of Phase Four will be the validation of the OCP by EFL teachers and BE learners, i.e., the target-users of the platform. In this Phase, the target-users will have the chance to utilize a prototype of the OCP. Users will map AVC using the prototype and provide feedback on this experience. This Phase will be a test to the OCP but also a Phase of data collection, in which participating teachers and learners will be sample crowds.

\section{References}

Bahrani, T., Tam, S. S., \& Zuraidah, M. D. (2014). Authentic Language Input Through Audiovisual Technology and Second Language Acquisition. SAGE Open, 4(3), 2158244014550611.

Bárcena, E., Read, T., Martín-Monje, E., \& Castrillo, M. D. (2014). Analysing student participation in Foreign Language MOOCs: a case study. EMOOCs 2014: European MOOCs Stakeholders Summit,11-17. 
Carvalho, T., Almeida, P. (2015). Matriz primária de caraterísticas de conteúdo AV procuradas por aprendentes de Inglês língua estrangeira, COIED 2015, Unpublished.

Carvalho, T., Almeida P., Balula A. (2017). Categorization of Business English Communicative Skills: A Proposal, EDULEARN17 Proceedings, pp. 6542-6549.

Crystal, D. (2005). The stories of English. Penguin UK.

Davis, L. L. (1992). Instrument review: Getting the most from a panel of experts. Applied nursing research, 5(4), 194-197.

Ghiglione, R., \& Matalon, B. (2001). The Survey-Theory and Practice. Publisher Celta, Oeiras.

Harrell, M. C., \& Bradley, M. A. (2009). Data collection methods. Semi-structured interviews and focus groups. Rand National Defense Research Inst santa monica ca.

Hockly, N.(2015). Developments in online language learning. ELT Journal, 69(3),308-313.

McNulty, A., \& Lazarevic, B. (2012). Best practices in using video technology to promote second language acquisition. Teaching English with technology,12(3),49-61. 